\title{
Investment Risk Analysis in the Use of Landfill Biogas for Electricity Generation
}

\author{
Alessandro Nunes Costa, Giordani Pacífico Medeiros, Wesley Calixto Pacheco, Aylton José Alves, Daywes \\ Pinheiro Neto and Elder Geraldo Domingues
}

Nucleus of Experimental and Technological Studies (NExT)

Federal Institute of Goias (IFG)

Campus of Goiania - Goias, 74900, Brazil

Phone/Fax number: 0055623209 7433, e-mail: alessandronun@hotmail.com

\begin{abstract}
The objective of this paper is to apply the risk analysis tools for power plants that use biogas produced in landfills to generate electricity. A stochastic modeling was developed for random variables that affect the cash flow of the project. The synthetic time series of the random variables were modeled by using the Mean Reversion Stochastic Processes (Geometric Ornstein-Uhlenbeck) associated with the Monte Carlo simulation method. This type of project fits on the Clean Development Mechanism (CDM) of the Kyoto Protocol. In order to quantify the baseline emissions, the carbon credits generated (Certified Emission Reductions - CER) and the potential of electricity generation, it was used the version 15 of the ACM-0001 methodology, approved and consolidated by the Intergovernmental Panel on Climate Change (IPCC). In this context, it will become possible to make a more accurate study of the economic feasibility of this type of venture. In order to verify the applicability of this methodology, a case study was presented to a landfill located in the Midwest region of Brazil. The results showed that the project is economically viable.
\end{abstract}

\section{Key words}

Certified Emission Reductions, landfill biogas, Monte Carlo simulation, risk analysis, Stochastic Process.

\section{Introduction}

The energy crisis of 2001 and the one that is happening in Brazil reinforce the need to expand and diversify energy generation sources in the country. Other factors such as rising oil prices, the seasonality of rainfall and environmental issues undermine the effectiveness of the current Brazilian energy model based mainly on the generation of hydroelectric and thermoelectric power plants using fossil resources. Therefore, it is important to encourage distributed and renewable generation so there will be an economic and technological model more sustainable. In this sense, the use of landfill biogas as electricity supply can be used as an energy alternative $[1,2]$.

The deposition of waste in landfills is still one of the most used and suitable methods for disposal of municipal solid waste (MSW) due to low cost, high absorption capacity and ease of operation compared to other forms such as incineration and composting. MSW usually have lots of partially or fully degradable materials such as food waste, garden waste, paper, wood and mud. Anaerobic decomposition of these materials in landfills produces gas containing approximately $50 \%$ of methane $\left(\mathrm{CH}_{4}\right)$, which is a greenhouse gas (GHG) whose global warming potential is 25 times that of carbon dioxide. Landfills represent one of the largest methane generators and tend to grow primarily due to population growth and increasing per capita waste generation $[1,3]$.

In order to extinguish the Brazilian landfills by the year 2014 through the implementation of landfills, was approved, in August 2010, Law No. 12,305/10, establishing the National Policy on Solid Waste in Brazil - NPRS. Despite all efforts, this target was not met, which does not relieve municipalities to comply with current legislation. In addition, this law provides for the adoption, development and improvement of clean technologies, since it has been proven their technical and environmental viability. As a result, both the government and the private sector must find solutions and implement appropriate techniques to achieve sustainable development for the management of landfills [4].

The estimate of methane emissions from landfills involves large uncertainties due mainly to the random variables involved in the process and insufficient information. The First Decay Order Method (FODM), developed by IPCC has been one of the most important and widely used model for the estimation of emissions of methane $[1,3]$.

It is common in the literature evaluate the potential of methane generation, the emission reductions, the electricity produced from landfill biogas as well as the economic viability of these kinds of projects by using deterministic analysis. In this paper, the economic viability was done taking into consideration random variables that affect the cash flow of the project. The random variables were modeled by using the Monte Carlo Simulation technique associated with appropriate stochastic process. The economic feasibility analysis was done using concepts and economic engineering criteria. 


\section{Methodology}

\section{A. Use of Biogas from Landfill to Produce Electricity}

The biogas generated in the landfill is spontaneous when the massive garbage is not in contact with air, providing the anaerobic process of organic waste fermentation, which results in biogas, which can be captured more efficiently with both vertical and horizontal internal drains. These drains are connected to high-density polyethylene pipes that lead biogas to the suction and condensation sector, being sent to burning. On the other hand, to generate electricity, rather than simply burning the biogas flares it should be picked up, driven and treated for combustion in a MotorGenerator Group (MGG) [1].

Besides the environmental benefits, the use of biogas as energy source has other advantages among which we can highlight: the use of a renewable source of energy; the proximity of the generating source to the consumer center (Distributed Generation), avoiding large investments in electricity transmission lines; and the diversification of energy sources.

Fig. 1 illustrates, in a simplified way, a landfill biogas use facility for electricity generation. The acronym MGG indicates the building that are located the Motor-Generator Group of internal combustion

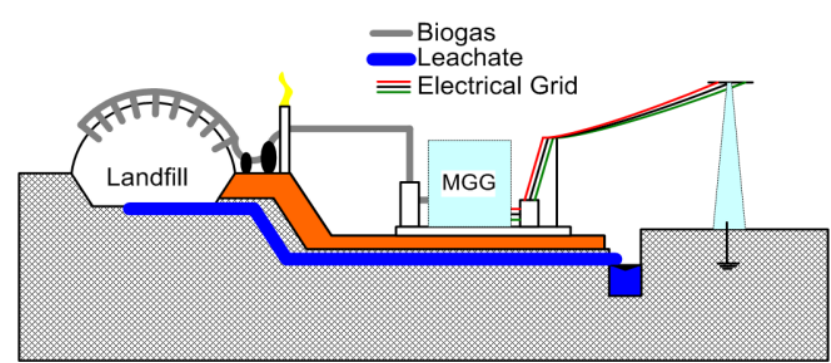

Fig. 1. Landfill biogas production and electricity generation.

The landfill biogas recovery can be done in several ways. Usually, in developed countries, where this practice is used, it generates electricity with internal combustion engines (Otto cycle) or gas turbines [1].

\section{B. ACM-0001 Methodology}

ACM-0001 methodology makes use of First Decay Order Method to estimate the biogas production in landfills [6,7]. According to [1], the FODM is the closest to reality and takes into account several parameters such as local climatic conditions, concentration of nutrients in the soil and composition of waste.

The FODM considers the generation of methane per MSW deposited on the $x$ year and during the later years. As each year new quantities of waste are deposited, the amount of methane generated in a given year is equal to the generation of waste deposited in the year $y$ plus generations of waste landfilled in previous years, as referenced in the year $y$ according to Eqn (1).

$$
B E_{C H_{4}, S W D S, y}=A_{G W} \cdot A_{D M} \cdot A_{W D}
$$

Where:

$$
\begin{gathered}
A_{G W}=\varphi(1-f) \cdot G W P_{C H_{4}}(1-O X) \\
A_{D M}=\frac{16}{12} F \cdot D O C_{f} \cdot M C F \\
A_{W D}=\sum_{x=1}^{y} \sum_{j} W_{j, x} \cdot D O C_{j} \cdot e^{-k_{j}(y-x)} \cdot\left(1-e^{-k_{j}}\right)
\end{gathered}
$$

In which, in Eqn (1), $B E_{C H 4, S W D S, y}$ is the methane emissions generated by waste deposited in the landfill between the beginning of the project activity and the end of year " $y$ " $\left(t C \mathrm{O}_{2 e}\right)$. In Eqn (2), $\varphi$ is the correction factor for the model, to account for model uncertainties, $f$ is the fraction of methane captured in the landfill and burnt or used in another form, $G W P_{C H 4}$ is the Global Warming Potential (GWP) for methane, valid through the relevant compromised period and $O X$ is the oxidation factor (reflecting the amount of landfill methane which is oxidized in the soil or in another material which covers the waste).

In Eqn (3), $F$ is the fraction of landfill methane gas (volume fraction), $D O C_{f}$ is the fraction of degradable organic carbon $(D O C)$ which may decompose, $M C F$ is the methane correction factor. For the expression Eqn (4) has, $W_{j, x}$ is the amount of type " $j$ " organic wasted deposited in the landfill in a specific year $x$ (tons), $D O C_{j}$ is the fraction of degradable organic carbon (by mass) in type " $j$ " waste and $k_{j}$ is the decay rate for the waste type $j$. The values $j, x$ and $y$ are defined as follows: $j$ is the waste type category (index), $x$ is the year of credit period: $x$ goes from the first year of the first credit period $(x=1)$ to the year for which the avoided emissions are calculated $(x=y)$ and $y$ is the year for which methane emissions are calculated.

Project emissions is the amount of greenhouse gas emissions in tons of carbon dioxide equivalent that would be issued with project implementation. For this calculation were considered fugitive emissions, those issued by the generator and the displaced emissions from utility power

If the landfill has passive ventilation system, it becomes necessary to implement forced ventilation system promoted by series of fans whose collection efficiency can reach more than $75 \%$ of the total produced biogas [1]. Thus, it can be considered that $15 \%$ of the total methane emissions are fugitive emissions. Thus, $85 \%$ of the methane from the landfill is burned in the Otto cycle engines generating energy or flare, as the stoichiometric balance:

$$
\mathrm{CH}_{4}+2 \mathrm{O}_{2} \rightarrow \mathrm{CO}_{2}+\mathrm{H}_{2} \mathrm{O}
$$

Thus, for each ton of $\mathrm{CH}_{4}$ that is burned has been the generation of 2.75 tons of $\mathrm{CO}_{2}$ that is emitted to the atmosphere. Moreover, one should consider the amount of power-shifted network. Thus, the amount of energy generated by the project implementation would be produced by another source. In Brazil, the interconnected power system, consisting of various types of sources that emit greenhouse gases. As a result, this font substitution also leads to reduction of emissions. 
The emission factor can be calculated according to the 02.2.0 version of the Tool to calculate the emission factor for an electricity system [8] also available on the ACM0001 methodology [6], as (6):

$$
F E=(0.5 M C)+(0.5 M O)
$$

In that $F E$ is the interconnected power system emission factor $\left(\mathrm{tCO}_{2} / \mathrm{MWh}\right), M C$ is the build margin and $M O$ is the operating margin.

The emission reductions in a given year $y$ (expressed in $\mathrm{tCO}_{2 \mathrm{e}}$ ) can be calculated as (7).

$$
\begin{gathered}
R E_{y}=M D_{y}+E D_{y} \\
M D_{y}=\left(M D_{p, y}-M D_{B L, y}\right) \cdot G W P_{C H_{4}} \\
E D_{y}=E L_{L F G, y} \cdot C E F_{\text {elec }, B L, y}+E T_{L F G, y} \cdot C E F_{\text {ther }, B L, y}
\end{gathered}
$$

Where: $R E_{y}$ is the reduction of emissions in a given year $\left(\mathrm{tCO}_{2 \mathrm{e}}\right) ; M D_{p, y}$ is the amount of methane that would have been destroyed during the year, in tons amount of methane that would have been destroyed during the absence of the project due to regulatory and/or contractual requirements, in tons of methane $\left(\mathrm{tCH}_{4}\right)$; and $G W P_{\mathrm{CH} 4}$ was determined in (2). It is noteworthy that the value of $M D_{B L, y}$ is usually zero because there is no Brazilian law that determines the amount of biogas to be burned. This is the same $f$ factor in the equation (1), but the latter expressed as a percentage.

In (9): $E L_{L F G, y}$ is the net amount of electricity produced using biogas, which in the absence of the project activity would have been produced by grid-connected power plants or by a captive power generation at the site or elsewhere, based on fossil fuel, during the year $y$, in megawatt hour (MWh); $C E F_{\text {elec }, B L, y}$ is the intensity of $\mathrm{CO} 2$ emissions from the baseline source of electricity displaced, in $t C \mathrm{O}_{2} / \mathrm{MWh}$; $E T_{L F G, y}$ is the amount of heat energy produced using landfill gas, which in the absence of the project activity would have been produced by fossil fuel burning boiler on site/off-site during the year $y$ in terajoule (TJ); and $C E F_{\text {ther,BL,y }}$ is the amount of fuel $\mathrm{CO} 2$ emissions used by oiler to generate thermal energy which is displaced by LFG based thermal power generation in $\mathrm{CO}_{2 e} / \mathrm{TJ}$.

\section{Electrical Power Useful Available}

To calculate the electrical power, first we did the calculation of the flow of methane every year that can be used, as Eqn 10 [5].

$$
Q_{\mathrm{CH}_{4}, \mathrm{y}}=\frac{\mathrm{BE}_{\mathrm{CH}_{4}, \mathrm{SWDS}, y}}{d_{\mathrm{CH}_{4}} \cdot G W P_{\mathrm{CH}_{4}}}
$$

In that $B E_{C H 4, S W D S, y}$ has been given in (1), $Q_{C H 4, y}$ is the methane flow rate $\left(\mathrm{m}^{3} /\right.$ year $), d_{C H 4}$ is the density of methane $\left(\right.$ ton $\left./ \mathrm{m}^{3}\right), G W P_{\mathrm{CH} 4}$ was determined in (2).

Calculated flow, can obtain useful electrical power generated by GMG in a given year by the Eqn 11[5]

$$
P o t_{y}=\frac{Q_{\mathrm{CH}_{4}, y} \cdot \mathrm{PCI}_{\mathrm{CH}_{4}} \cdot E \cdot \eta}{31,536,000}
$$

Where: Pot $_{\text {, }}$ is the useful electrical power available each year (kW), $Q_{C H 4, y}$ was given in (10), $P_{C I} I_{C H}$ is the lower calorific value $\left(\mathrm{kJ} / \mathrm{m}^{3}\right), E$ is the gas collection efficiency, $31,536,000$ value is the conversion factor (s/year) and $\eta$ is the electrical efficiency of GMG.

\section{Economic Feasibility}

In the analysis of the economic viability were applied concepts and criteria of economic engineering such cash flows, discount rate, NPV, IRR and Payback. Cash flow was obtained considering the due fees and taxes, equipment depreciation, among others, during the analysis of the investment period.

\section{E. Risk Analysis}

Studies of biogas generation presented so far in the literature do not take into account the random variables involved in the process, being therefore deterministic. The risk analysis is more reliable and safe than the deterministic one.

The power generated by MGG that uses biogas from landfill depends directly on methane flow rate and the methane emissions generated by waste deposited in the landfill $\left(B E_{C H 4, S W D S, y}\right)$.

The behavior of the amount of organic waste of type $j$ deposited in the landfill for the scenario $i$ through a time period $x,\left(W j_{i, x}\right)$ can be modeled as times series which are, in turn, described by Stochastic Processes. This random variable, that presents an upward trend over time, can be modeled by using the stochastic process known as a Geometric Brownian Motion of Mean Reversion (GBMMR), also known Geometric Ornstein-Uhlenbeck [9], associated with the Monte Carlo simulation method (MCSM).

The amount of organic waste of type $j, W j$, does not take negative values. It is reasonable to imply that its probability distribution function is log-normal. We can thus operate a variable change $z=\ln (W j)$. The Mean Reversion Process is then applied to the napierian logarithm of the amount of organic waste of type $j$ variable $z$ instead of applying it to $W j$.

The mathematical equation for GBM-MR is shown in (12).

$$
d z=z_{t+1}-z_{t}=\eta_{W j} \cdot\left(\bar{z}-z_{t}\right) \cdot d t+\sigma_{W j} \cdot \varepsilon_{W j} \cdot \sqrt{d t}
$$

In (12) $\eta_{W j}$ refers to mean reversion speed of the MSW type $j ; \sigma_{W j}$ refers tothe MSW volatility; $\varepsilon_{W j} \sqrt{d t}$ is the Wiener process, where $\varepsilon$ is a random number with standard normal distribution $(\mathrm{N}(0,1)) ; \bar{z}$ is the global average of the MSW for the historical period and $t$ is the time. With $\mathrm{d}\left[\ln \left(W_{j}\right)\right]$ being the increment to $\ln (W j)$, then: 


$$
d[\ln (W j)]=\frac{d W j}{W j}
$$

By substituting (13) in (12) we have:

$$
\frac{d W j}{W j}=\eta_{W j} \cdot(\ln (\bar{W})-\ln (W j)) \cdot d t+\sigma_{W j} \cdot \varepsilon_{W j} \cdot \sqrt{d t}
$$

In (12), $\bar{W}$ is the average value of MSW, obtained from historical data.

By applying Ito's lemma we have the following expression:

$W j_{t+1}=W j_{t} \cdot e^{\left\{\left[\eta_{W j} \cdot\left(\ln (\bar{W})-\ln \left(W_{j}\right)\right)-\frac{\sigma_{W j}^{2}}{2} \cdot\right] d t+\sigma_{W_{j}} \cdot \varepsilon_{W j} \cdot \sqrt{d t}\right\}}$

Similarly, this model can be used to modelall random variables that affect the cash flow of the project. The other random variables considered were the price of CER and electricity pricesobtained from auctions in the Brazilian Regulated Electricity Market [10].

\section{Estimating Parameters}

For the GBM-MR, the parameters reversion speed $\eta$, mean reversion value $\bar{z}$ and volatility $\sigma$ were estimated from the historic data series $z_{t}$, using the methodology developed by Dixit and Pindyck $[11,12]$. For the considered series, we operated a simple linear regression with $\ln \left(z_{t}\right)-\ln \left(z_{t-1}\right)$ as the dependent variable, and $\ln \left(z_{t-1}\right)$ as the independent variable, given by:

$$
\ln \left(\frac{z_{t}}{z_{t-1}}\right)=a+(b-1) \cdot \ln \left(z_{t-1}\right)
$$

The parameters have been calculated from the estimates obtained from the regression using (17), (18), (19), where $\sigma_{\varepsilon}$ is the standard regression error.

$$
\begin{array}{r}
\eta=\frac{-\ln (b)}{\Delta t} \\
\bar{z}=\exp \left[\frac{a}{1-b}+\frac{\sigma_{\varepsilon}}{(1-b)^{2}}\right] \\
\sigma=\sigma_{\varepsilon} \sqrt{\frac{2 \ln (b)}{\left(b^{2}-1\right) \Delta t}}
\end{array}
$$

\section{Case Study}

This research work was conducted in the city of Anapolis, Estate of Goias, and aimed at validating the risk analysis model created to assess the implementation of a landfill plant. The Study of biogas generation in the landfill was made for the period 2,000 to 2,100. There, however, the economic feasibility analysis was considered only the period for obtaining carbon credits (21 years).Simulations were conducted with 2,000 scenarios.

\section{A. Adopted Data and Estimating Parameters}

Table I to Table III provide the values of the key data used in the simulation for obtaining the baseline scenario. Table II shows the characterization of the waste by type gravimetric composition, degradable organic carbon ratio and decomposition rate by type of waste. Table III provides the data used for obtaining the project scenario.

Table I - Data used to obtain baseline

\begin{tabular}{|c|c|}
\hline Data & Values \\
\hline Implementation of landfill & December $/ 1999$ \\
\hline Year closure of the landfill & 2050 \\
\hline Waste generation rate & $0,76 \mathrm{~kg} / \mathrm{hab} /$ day \\
\hline Municipal waste collection rate & $100 \%$ \\
\hline Calorific value lower of methane & $8.500 \mathrm{kcal} / \mathrm{m}^{3}$ \\
\hline Methane density & $0,7167 \mathrm{~kg} / \mathrm{m}^{3}$ \\
\hline$\varphi$ & 0,75 \\
\hline$f$ & 0 \\
\hline$G W P_{C H 4}$ & 25 \\
\hline$O$ & 0,1 \\
\hline$F$ & 0,5 \\
\hline$D O C_{f}$ & 0,5 \\
\hline$M C F$ & 1,0 \\
\hline
\end{tabular}

Table II - Characterization of the residue by type

\begin{tabular}{|c|c|c|c|}
\hline Waste type (j) & $\begin{array}{c}\text { Gravimetric } \\
\text { composition } \\
(\mathbf{\%})\end{array}$ & $\begin{array}{c}\text { DOCj } \\
(\mathbf{\%} \text { wet } \\
\text { basis) }\end{array}$ & $\mathbf{K j}$ \\
\hline $\begin{array}{c}\text { Wood and wood } \\
\text { products }\end{array}$ & 5 & 43 & 0.035 \\
\hline $\begin{array}{c}\text { Pulp, paper and } \\
\text { cardboard }\end{array}$ & 17 & 40 & 0.07 \\
\hline $\begin{array}{c}\text { Food waste, beverages } \\
\text { and tobacco }\end{array}$ & 45 & 15 & 0.40 \\
\hline Textiles & 3 & 24 & 0.07 \\
\hline Garden waste & 0 & 20 & 0.17 \\
\hline $\begin{array}{c}\text { Glass, plastic and } \\
\text { other non-inert }\end{array}$ & 30 & 0 & - \\
\hline
\end{tabular}

Table III - Data used to obtain project scenario

\begin{tabular}{|l|c|}
\hline \multicolumn{1}{|c|}{ Parameter } & Values \\
\hline Biogas collection rate & $85 \%$ \\
\hline Power each MGG & $330 \mathrm{~kW}$ \\
\hline Efficiency of MGG & $35 \%$ \\
\hline Operation of MGG & $8560 \mathrm{~h} /$ year \\
\hline Useful life of the MGG & 21 yeas \\
\hline Emission factor network & $0,4322 \mathrm{tCO} / \mathrm{MWh}$ \\
\hline Duration of the project & 21 years \\
\hline Start of project & Jan/2017 \\
\hline Project completion & Dec/2037 \\
\hline
\end{tabular}

Table IV - Data used in the analysis of economic viability

\begin{tabular}{|c|c|}
\hline Data & Values \\
\hline Minimum attractive rate (MAR) & $12 \%$ \\
\hline Social Integration Program, & $0,65 \%$ Revenue \\
\hline Social Integration Program, & $3 \%$ of Revenue \\
\hline Social Security Financing Contribution & $8 \%$ \\
\hline Administration Costs & $2 \%$ of initial investment \\
\hline Custos de O\&M & $\mathrm{R} \$ 200.000($ by year) \\
\hline Network connection cost & $\mathrm{R} \$ 30.000,00$ \\
\hline Gas compression cost & $690 \mathrm{R} \$ / \mathrm{m}^{3} / \mathrm{h}$ \\
\hline Purification system $\left(\mathrm{H}_{2} \mathrm{O}\right)$ & $0,0138 \mathrm{R} \$ / \mathrm{m}^{3}$ \\
\hline Purification system $\left(\mathrm{H}_{2} \mathrm{~S} / \mathrm{Siloxine}\right)$ & $0,0138 \mathrm{R} \$ / \mathrm{m}^{3}$ \\
\hline Purification system $\left(\mathrm{CO}_{2}\right)$ & $0,0138 \mathrm{R} \$ / \mathrm{m}^{3}$ \\
\hline Compression system & $690 \mathrm{R} \$ / \mathrm{m}^{3} / \mathrm{h}$ \\
\hline Depreciation & 10 years $($ linear $)$ \\
\hline
\end{tabular}


Table IV shows the data used for the economic feasibility analysis of the Project. Table V shows the estimated parameters for the GBM-MR obtained from the annual historical data of the following random variables: 1) MSW $\left(W_{t}\right)$ : period of 2000 to $\left.2050 ; 2\right)$ Price of Electricity $\left(E_{t}\right)$ : period of 2017 to 2037 and 3) Price of CER $\left(C_{t}\right)$ : period of 2017 to 2037.

Table V - Estimated parameters for $W_{t}, E_{t}$ and $C_{t}$

\begin{tabular}{|c|c|c|c|c|c|}
\hline \multicolumn{2}{|c|}{ MSW } & \multicolumn{2}{c|}{ Energy Price } & \multicolumn{2}{c|}{ CER Price } \\
\hline $\bar{W}$ & $79,714,779$ & $\bar{E}$ & 120.01 & $\bar{C}$ & 10 \\
\hline$\eta_{w}$ & 0.015 & $\eta_{E}$ & 0.2494 & $\eta_{C}$ & 0.8494 \\
\hline$\sigma_{w}$ & 0.05 & $\sigma_{E}$ & 0.2311 & $\sigma_{c}$ & 0.2 \\
\hline
\end{tabular}

\section{B. Results}

Fig. 2 shows 2,000 scenarios for the MSW deposited since the opening to the closing of the landfill.

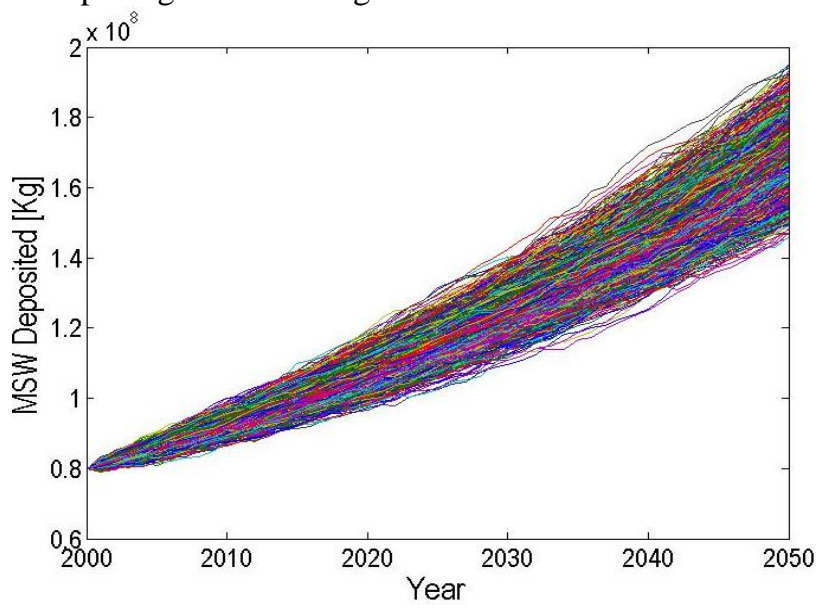

Fig. 2. Amount of MSW deposited in the landfill

Fig. 3 and Fig. 4 show 2,000 scenarios for the prices of electricity and CER, respectively, from 2017 to 2037, period that was the considered for economic viability of the project.

Fig. 5 presents the estimates of methane emission in $\mathrm{tCO}_{2 \mathrm{e}}$ for the period of 2,000 to 2,100 for one scenario. It is also shown the methane generation curves for each type of material that constitutes this landfill's waste.

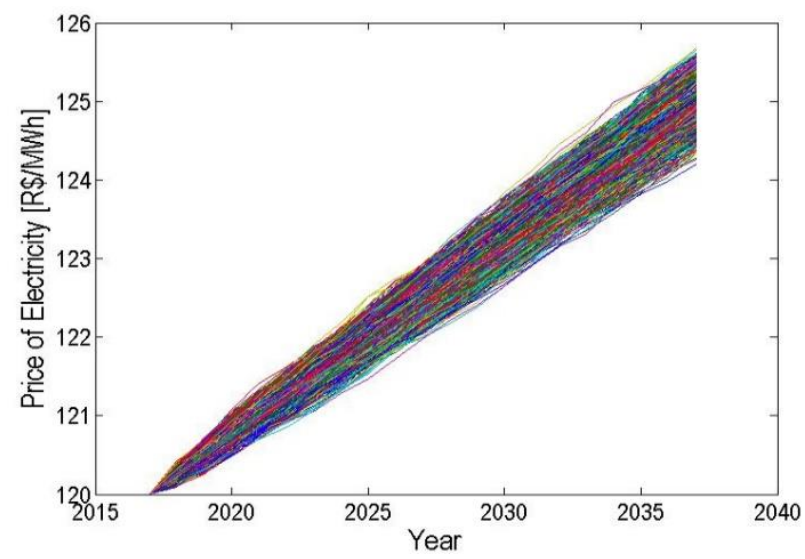

Fig. 3. Price of Electricity

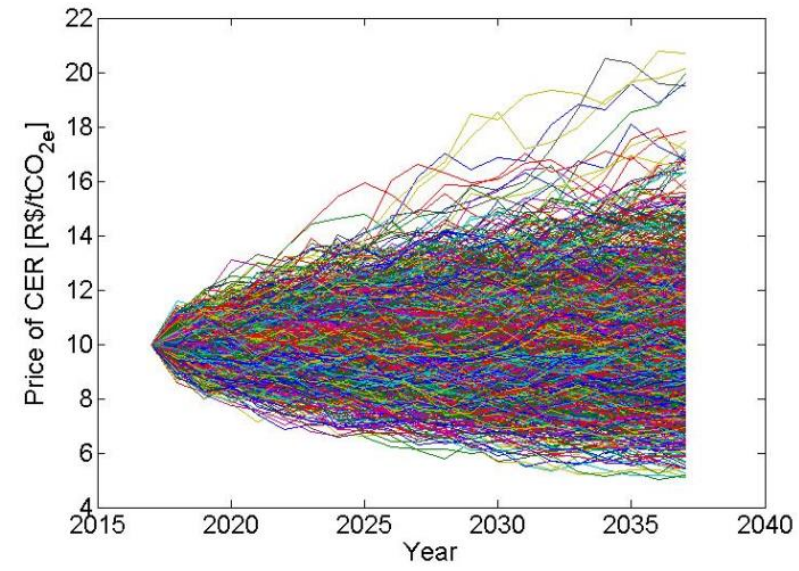

Fig. 4. Price of CER

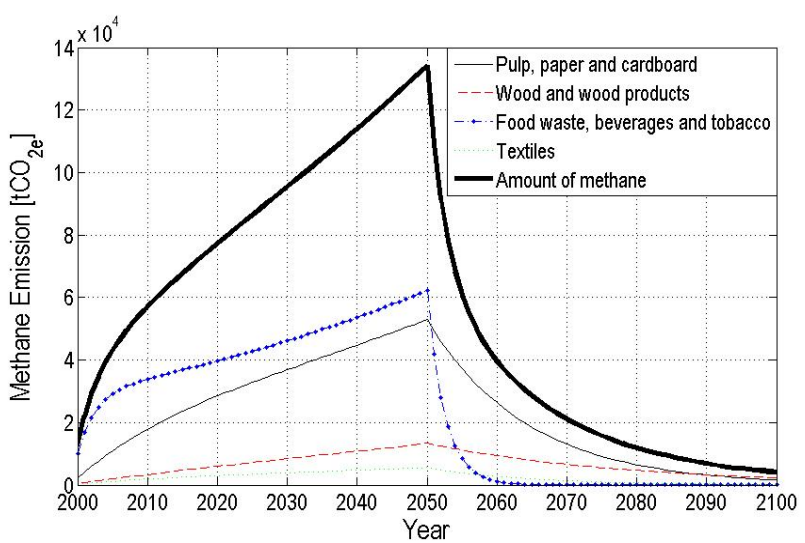

Fig. 5. Methane emission estimates for one scenario

Fig. 6 shows the estimates for the potential emission of methane in $\mathrm{tCO}_{2 \mathrm{e}}$ for the period of 2,000 to 2,100 for 2,000 scenario. It is interesting to highlight that after the projected year of closure of the landfill (2050) there will be a continued production of methane which must be used or at least controlled to avoid risks. Note that the maximum methane production occurs in the closing year of the landfill.The worst scenario of methane production exceeds 70,000 tCO2e whereas the best scenario exceeds 300,000 tCO2e.

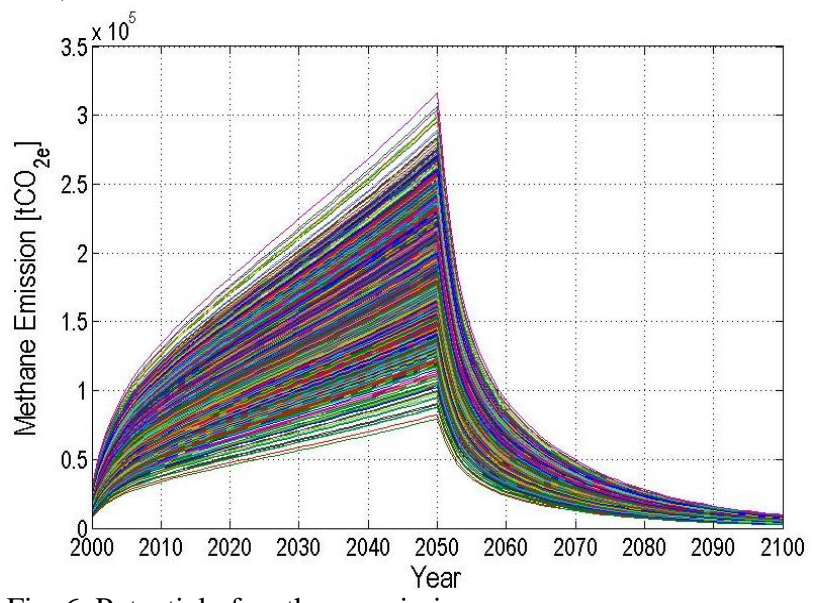

Fig. 6. Potential of methane emission

Cash flow was done considering the revenues from CER and sale of electricity. We also considered taxes and fees in force in Brazil. NPV probability density function is shown in Fig. 7. In this case, it can be verified that probability of no return on investment (PNRI) is equal 
zero, due to the fact that in all scenarios the NPV values are positives.

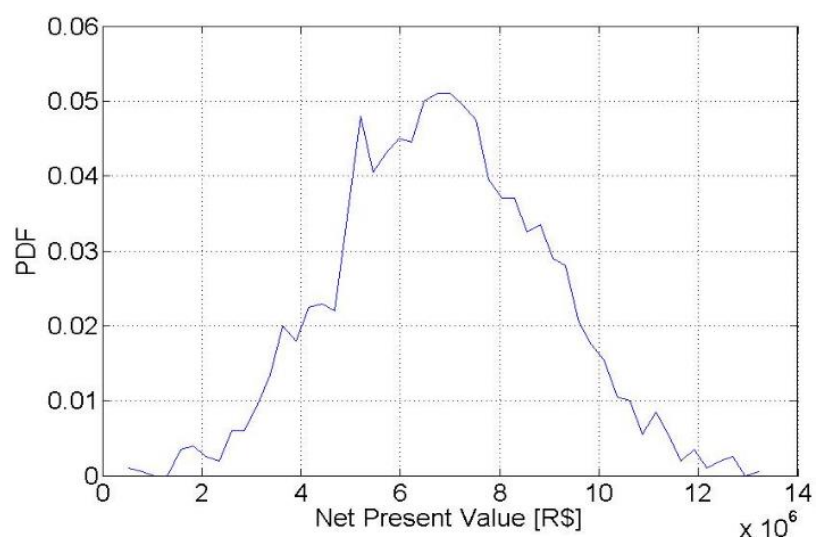

Fig. 7. NPV probability density function

Table V shows the expected value $(\mu)$, standard deviation $(\sigma)$ and maximum and minimum values of NPV, IRR and Payback, obtained through its probability density functions.

Table V - Summary of the risk analysis

\begin{tabular}{|c|c|c|c|}
\hline & NPV $(\mathbf{R} \$)$ & IRR (\%) & Payback \\
\hline$\mu$ & $6,945,300.00$ & 29,87 & 4.9057 \\
\hline$\sigma$ & $2,066,200.00$ & 3,25 & 0.8496 \\
\hline Max & $14,049,000.00$ & 37,84 & 11.9939 \\
\hline Min & $766,460.00$ & 15,70 & 3.6084 \\
\hline
\end{tabular}

It can be noted that the project is economically feasible beause: 1) the expected value of NPV is approximately 7 million of reais and even in the worst scenario is economically feasible because the NPV is approximately 700 thousand reais; 2) In all scenarios the IRR is greater than MAR considered (12\% a.y.) and 3) the worst value of the payback period is approximately 12 years, less than the period of cash flow considered.

\section{Conclusion}

This paper presented a methodology for risk analysis of investments projects that use biogás from landfill to generate electricity. From the appropriate stochastic modelling were possible to predict the behaviour of the price of electricity the price of carbon credits and amount of MSW, main risk variables that affect the cash flow of the project. In the presented case study, were obtained 2,000 scenarios for biogas production for the period of 101 years. It has been found that the higher values occur in the closing year of the landfill (2050).
To obtaining the cash flow and the economic feasibility analysis, it was considered the period of 21 years, that corresponds to the maximum period of obtaining the carbon credits.

Risk analysis showed the economic viability of the project. In all scenarios was obtained: NPV greater than zero, IRR greater than the TMA and Payback lower than the period considered for the project's cash flow.

\section{Acknowledgement}

The authors would like to thank the Environmental Department of the Municipality and the landfill managers, for providing the necessary data to undertake this research project, and the Foundation for Research Support of the State of Goias (FAPEG), agency fosterer who gave support to this research.

\section{References}

[1] ENSINAS, A. V. Study of the generation of biogas in the Delta landfill. Thesis, State University of Campinas, Campinas, SP, Brazil, 2003 (in Portuguese).

[2] E. G. Domingues, Análise de Risco para Otimizar Carteiras de Ativos Físicos em Geração de Energia Elétrica. PhD thesis, Federal University of Itajuba, Itajuba-MG, 2003.

[3] IPCC. IPCC Guidelines for National Greenhouse Gas Inventories. National Greenhouse Gas Inventories Programme. United Nation Environmental Programme. 2006.

[4] BRAZIL. Law No. 12.305/10 that creates the National Policy on Solid Residues (NPSR). Official Gazette of the Federative Republic of Brazil, Executive Power, Brasilia, DF, Brazil, August 3, 2010, Section 1, page 2 .

[5] UNFCCC. United Nations Framework Convention on Climate Change. Clean Development Mechanism Methodology Booklet, Fifth Edition, November 2013, ISBN 978-92-9219-118-4.

[6] UNFCCC Methodology ACM0001: Consolidated baseline methodology for landfill gas project activities Version 17. April 2015.

[7] UNFCCC. Methodological Tool: Emissions from solid waste disposal sites: version 07.0. April 2015.

[8] UNFCCC. Methodological Tool: Emission factor for an electricity system: version 02.2.0.Available in: 〈http://www.unfccc.org> Acessed in: April 2015.

[9] HULL, J., Options, Futures and Other Derivatives, Prentice-Hall, second edition, 1993.

[10] ANEEL. Brazilian Electricity Regulatory Agency. Auctions Renewable Energies. Available in: < http://www.aneel.gov.br. $>$.Acessed in: April 2015.

[11] A. K. Dixit and R. S. Pindick, Investment Under Uncertainty. Princeton,New Jersey: Princeton University Press, 1994.

[12] J. M. Wooldridge, Introductory Econometrics: A Modern Approach. South-Western College Publishing, 2000. 